\title{
Nuevas formas cerámicas de Vascos
}

\author{
Ricardo Izquierdo Benito*
}

En este breve artículo, en homenaje a nuestro querido amigo Guillermo Rosselló-Bordoy, queremos presentar un conjunto de piezas cerámicas procedentes de las excavaciones que, desde hace años, venimos llevando a cabo en la ciudad hispanomusulmana de Vascos (Navalmoralejo, Toledo), y que suponen una cierta novedad, formal o decorativa, en relación a lo que hasta el presente hemos publicado sobre los hallazgos realizados. La novedad radica, por tanto, no ya en tratarse de piezas inéditas en el conjunto de la cerámica conocida de al-Andalus, sino en resultar desconocidas hasta ahora en el contexto del yacimiento. Así, vienen a complementar la tipología que en su momento elaboramos con lo hasta entonces conocido (IZQUIERDO, 1986a).

Hemos de señalar que, a pesar de la gran cantidad de cerámica recogida en las sucesivas campañas anuales realizadas, son muy pocas, desgraciadamente, las piezas mínimamente completas que aparecen. Los miles de fragmentos que cada año son recogidos, por su reducido tamaño parecen corresponder a un material empleado como degrasante en el barro de los tapiales de los muros de las edificaciones. En el contexto de su hallazgo, se trata, por tanto, de una cerámica utilizada como material de construcción, una vez superada, por rotura, la función original para la que fue fabricada. No obstante, a pesar de esta circunstancia, nos puede ofrecer una información de interés, aun no perdiendo de vista ciertas limitaciones, pues siempre puede quedar la duda de si esa cerámica se utilizó en Vascos con fines domésticos o si fue traída de fuera para ser empleada como material de construcción. En cualquier caso, de lo que se trata es de cerámica andalusí que, por su abundancia y variedad, debe ser analizada. Es lo que ya hemos hecho con anterioridad, tanto por lo que respecta a la cerámica común (IZQUIERDO, 1987) como a la decorada (IZQUIERDO, 1983 b).

La escasez de piezas completas posiblemente haya que atribuirla al proceso de despoblación de la ciudad. Hasta el presente en las distintas zonas excavadas no se ha detectado un nivel de destrucción violenta. Ello hace suponer que sus habitantes la abandonaron gradualmente -o en masa- y posiblemente llevándose consigo sus enseres domésticos, entre los cuales algunas piezas de cerámica. Por lo cual apenas quedaría nada en las viviendas y de ahí que en su excavación sean muy pocas las que se encuentran, contrastando con la gran cantidad de fragmentos.

La cerámica que hasta el año 1988 ha aparecido en Vascos ha sido presentada en las correspondientes memorias publicadas (IZQUIERDO, 1979, 1983 a, 1986 b y 1994) y en otros estudios ya anteriormente señalados. Desde esa fecha, los trabajos han proseguido en la vertiente exterior sur de la alcazaba, dejando al descubierto un amplio sector de la ciudad. Las piezas cerámicas que aquí presentamos corresponden a hallazgos efectuados en esta zona. Se trata, por tanto, de

* Universidad de Castilla La Mancha 
una selección de piezas inéditas, que suponen, como ya se ha señalado, una novedad con respecto a lo hasta ahora conocido en el yacimiento. Por interesarnos especialmente sus elementos formales, no nos vamos a referir a su lugar concreto de hallazgo; ello se reflejará en la memoria cuando ésta sea publicada.

Para su presentación diferenciaremos aquellas piezas completas -o mínimamente completas- de aquellas que resultan fragmentadas pero que suponen un significativo aporte formal o decorativo. En la terminología empleada para la denominación de las piezas seguimos, en gran medida, la propuesta por Guillermo RosellóBordoy (1978 y 1991).

\section{PIEZAS COMPLETAS}

En este apartado incluimos no solamente piezas que han aparecido enteras, sino también otras que, aunque estén incompletas, su forma originaria es perfectamente reconstruible. En algunos casos se trata de piezas formalmente ya conocidas, pero que presentan alguna variante de interés.

\section{Ollas}

Posiblemente, junto con los cántaros, es el tipo de pieza más abundante en Vascos, lo cual es lógico dada su obligada necesidad en las operaciones culinarias. Los fragmentos que se han encontrado han sido muy numerosos, aunque las piezas mínimamente completas, por el contrario, han sido muy escasas (IZQUIERDO, 1979: f. 4 n I, lám. XVII n I; 1983 a: f. 36 nº 6; 1994: f. 38 $n^{\circ} 3$ y 4). Todas ellas están quemadas por el uso, y la mayoría presentan la característica forma de panza globular, con gollete en escotadura y dos pequeñas asas que arrancan del labio o de la parte inferior de la escotadura. Los dos ejemplares que aquí presentamos se escapan, en algunos aspectos, a estas premisas.

La novedad del primero radica no tanto en su forma -pues es idéntica a la de otras muchas ollas- sino en su tamaño, ya que solamente alcanza $7 \mathrm{cms}$ de altura y el diámetro de la boca es de $8,5 \mathrm{cms}$ (fig. I $\mathrm{n}^{\circ}$ |). Se trata de una pequeña olla, panzuda, con gollete sin escotadura rematado en un labio plano y con dos asas simétricas -bastante acusadas en proporción al tamaño de la pieza- que se desarrollan en la parte central del cuerpo.

El otro ejemplar, aunque incompleto, presenta dos novedades: el tener cuatro asas y el ofrecer una decoración incisa y pintada (fig. I $n^{\circ} 4$ ). No tiene cuello señalado y en la parte interior de la boca -con un diámetro de 16 cms- se desarrolla un acusado reborde o cama para soportar una tapadera. Las asas arrancan de la parte inferior del labio hasta la mitad del cuerpo. Es la primera olla con cuatro asas que se ha detectado en Vascos. La decoración se desarrolla en la mitad superior del cuerpo y consiste en bandas alternas con incisiones onduladas y motivos pintados en blanco, de temas aparentemente geométricos, difíciles de precisar por el estado de la pieza que en gran parte se encuentra quemada.

Una pieza de forma algo parecida a ésta, también con cuatro asas y decoración pintada aunque completamente diferente, se encontró en Calatalifa (RETUERCE, 1984: f. 2 D)

\section{Tinajas}

Las tinajas, para el necesario almacenamiento de líquidos, debieron de ser muy abundantes en Vascos dado la gran cantidad de fragmentos encontrados, de factura muy diversa. Se trata de piezas grandes, con una altura entre los 60 y los $80 \mathrm{cms}$, y pueden tener una superficie completamente lisa o presentar algún elemento decorativo -inciso o estampillado- en la parte superior. Aunque pueden tener asas, normalmente de orejetas, éstas, por su forma y su tamaño, vienen a resultar más como apéndices decorativos que como elementos estrictamente funcionales (IZQUIERDO, 1979: f. 5 n $^{\circ} 2$ y f. 6). En ocasiones, estas piezas se encontraban enterradas en el interior de las viviendas, con la boca a ras del suelo. Así aparecieron los dos ejemplares que aquí presentamos. Esta circunstancia es lo que ha posibilitado que estas piezas se hayan conservado intactas, pues lo normal es que, debido a su tamaño, aparezcan siempre completamente fragmentadas. 
Fig. $2 n^{\circ}$ I: tinaja de forma globular, de unos $77 \mathrm{cms}$ de altura, con un pequeño gollete, rematado en una boca de 34,5 cms de diámetro, formada por un labio remarcado al exterior. En la parte superior, arrancando de la base del gollete, tiene dos asas simétricas de aletas, que presentan una sencilla decoración de digitaciones en su borde. El barro es de color ocre, de regular calidad. Debajo del gollete se desarrolla una moldura también con digitaciones. Un ejemplar parecido a éste, aunque fechado en época nazarí (siglos XIII-XV), se encontró en la alcazaba de Almería (AGUADO, 1991: p. 34, f. 2ª).

Fig. $2 n^{\circ}$ 2: se trata de una tinaja de forma ligeramente cilíndrica, de unos $70 \mathrm{cms}$ de altura, con un cuello acusado rematado en una boca de $32 \mathrm{cms}$ de diámetro, formada por un grueso labio remarcado al exterior. En la parte superior, arrancando de la base del cuello, tiene dos asas simétricas en forma de aletas. El barro es de color ocre, de regular calidad. Presenta una decoración muy sencilla, consistente en una banda de incisiones onduladas en la parte inferior del cuello y en unos grupos de pequeñas incisiones circulares en la parte superior de la boca.

Una tinaja también completa, de características muy similares a éstas, aunque sin ningún elemento decorativo, también apareció anteriormente en Vascos (IZQUIERDO, 1979: f. 6). Por su forma, estas tinajas podrían corresponder al tipo C de Roselló-Bordoy (1978: f. 20).

\section{Cuencos}

Se trata de piezas de pequeño tamaño, con repie anular, normalmente recubiertas por un vidriado. En algunos casos, parecen corresponder a imitaciones de formas orientales.

Fig. $3 n^{\circ}$ I: fragmento de un pequeño cuenco de pared fina, con labio exvasado al exterior. Presentamos esta pieza por tener una decoración de cuerda seca total en su interior, cuyos motivos parecen imitar motivos orientales. Se combinan los colores blanco, verde, morado, melado amarillento y melado verdoso. El exterior está recubierto por un vidriado melado.
Fig. $3 n^{\circ} 2$ : pequeño cuenco con repie anular de 6 cms de diámetro, de cuerpo semiesférico, rematado en un labio redondeado. La boca tiene un diámetro de $12 \mathrm{cms}$. Toda la pieza está recubierta por un vidriado melado amarillento y en el interior conseva algunos restos de decoración en manganeso.

Fig. $3 n^{\circ}$ 3: pequeño cuenco con repie anular de 5,5 cms de diámetro, de cuerpo ligeramente carenado, rematado en un labio fino exvasado al exterior. La boca tiene un diámetro de $13 \mathrm{cms}$. Toda la pieza está recubierta por un vidriado blanco.

Fig. $6 n^{\circ}$ 4: fragmento de un pequeño cuenco o platillo de fondo plano de $6 \mathrm{cms}$ de diámetro y pared inclinada rematada en un labio plano de $1 \mathrm{l}$ cms de diámetro. La pasta es de color ocre. Ofrece la peculiaridad de presentar una decoración de motivo impreciso, tanto en su interior como en el exterior, incluida la base, elaborada con manganeso. Platillos similares a éste, aunque sin decoración, ya se encontraron anteriormente en Vascos (IZQUIERDO, 1994: f. $\left.37 n^{\circ} 6\right)$.

\section{Cazuela}

En Vascos ya habíamos encontrado varios tipos de cazuelas mínimamente completas (IZQUIERDO, 1983 a: f. 37 nº I, lám. IX nº 8; 1994: f. 39 nº 3 y 4 y f. $40 n^{\circ}$ 3). Todas ellas tienen una forma muy similar, siendo bastante planas, de boca muy ancha, con dos pequeñas asas que normalmente arrancan de la boca hasta la mitad del cuerpo. La pasta suele ser de regular calidad y siempre están quemadas por el uso sobre el fuego. Debio de ser un tipo de piezas bastante frecuente, utilizadas para la cocción de alimentos.

El ejemplar que aquí presentamos supone una cierta novedad con respecto a los anteriores, ya que tiene un pequeño gollete en escotadura y las asas -más desarrolladas y con un apéndice decorativo en la parte superiorarrancan por debajo del mismo hasta la base (fig. $4 n^{\circ}$ I). El diámetro de la boca es de 22 cms y está rematada por un labio redondeado al exterior. Presenta unas pequeñas incisiones en la parte inferior. 
Una pieza con un perfil bastante parecido al de ésta, aunque tiene un reborde en el interior para sujetar una tapadera, fechada en la primera mitad del siglo XIII, se encontró en Jijona (Alicante) (AZUAR, 1985: p. 69, f. 92).

\section{Anafe}

Aunque debió de tratarse de un tipo de pieza bastante frecuente también en las labores de cocina, son muy pocos los restos de anafes que se han encontrado en Vascos. De ahí la novedad del ejemplar, casi completo, que aquí presentamos (fig. $5 n^{\circ}$ 3). Tiene una forma troncocónica, con un grueso labio en la parte superior, al interior de la cual se desarrollan tres apéndices que servían de soporte a la pieza que se colocaba sobre el anafe. La boca, por la que se introducía el fuego, es de forma triangular y se abre en la pared. A lo largo de su cuerpo presenta una decoración consistente en dos bandas de incisiones paralelas, entre las que se desarrolla una banda de incisiones onduladas. La pasta, de mala calidad, es de color grisácea, ennegrecida por el uso. El díametro de la parte superior es de $21 \mathrm{cms}$ y el de la base de 33 .

Del casco urbano de Murcia procede un ejemplar, fechado en los siglos X-XI, bastante parecido a este de Vascos (NAVARRO, 1986: p. 165, pieza $\left.n^{\circ} 355\right)$. Este tipo de piezas se encuadra en la serie 34 de la clasificación morfológica realizada por Sonia Gutiérrez para la zona del sureste peninsular; en la correspondiente a la cerámica fabricada a mano, presenta un ejemplar también bastante parecido al de Vascos (1996: p. 96-97, f. 30).

\section{Jarrito}

Han sido varios los jarros y jarritos, de formas muy diversas, que se han encontrado en Vascos (IZQUIERDO, 1986 a: pp. II4-I16). El ejemplar que aquí presentamos ofrece una forma nueva hasta ahora no conocida en el yacimiento (fig. $6 \mathrm{n}^{\circ}$ 3). Se trata de una pieza muy incompleta pero de la que se puede reconstruir su forma originaria. Corresponde a un jarrito, de 10,5 cms de altura y fondo plano de $5 \mathrm{cms}$ de diámetro, con cuerpo bajo ligeramente carenado. Tiene un asa, de sección triangular, que arranca del cuello hasta la carena. En la mitad del cuerpo se desarrollan dos incisiones paralelas. Lo peculiar de esta pieza es su ancha boca trilobulada, con piquera para verter. Está recubierta por un vidriado verdoso al exterior y melado amarillento al interior.

\section{Tapadera}

Han sido muy diversas las formas de tapaderas que se han encontrado en Vascos (IZQUIERDO, 1983: f. 23 n I 18-25, lám. IX nº 6; 1986 a: pp. I I7-I I 8 y 1994: ff. 34 y 35). El ejemplar que aquí presentamos supone una novedad y corresponde a una pequeña pieza, con pedúnculo central, base plana y un amplio borde saliente (fig. I n³). El diámetro total es de 9,5 cms. Se utilizaría para encajar en una pieza de boca no muy ancha, y muy posiblemente para no ser utilizada al fuego, ya que no conserva restos de quemado. La pasta es de color ocre-anaranjado, de bastante buena calidad, aunque la factura es algo tosca.

\section{Ataifores}

Han sido también bastante abundantes los fragmentos de ataifores encontrados en Vascos, aunque muy pocas piezas mínimamente completas (IZQUIERDO I979: ff. 37, 38, 39, 40 y 43, lám. XX; 1983 b: ff. $26,27,28 n^{\circ}$ I y 2 y f. $29 ; 1986$ b: f. $13 n^{\circ}$ I y 4; 1994: f. 39 n 2 y ff. 42 y 48). Su tamaño es muy diverso -desde piezas bastante grandes hasta otras más reducidas que más bien parecen cuencos- y puede considerarse que todas ellas presentan una decoración de verde y manganeso o de manganeso en su interior, estando recubiertas por un vidriado melado al exterior. Lo más corriente es que todas ellas tengan un repie anular. Los ejemplares que aquí presentamos ofrecen la novedad de no estar recubiertos por ningún vidriado.

Fig. I $n^{\circ}$ 2: es un pequeño ataifor -casi un cuenco-, de cuerpo ligeramente carenado, rematado en un labio inclinado al exterior y con fondo plano, algo inestable. A lo largo de la carena tiene una incisión bastante profunda. La pasta es de color anaranjada, bastante bien decantada. Todo el labio está recubierto por una pintura de color marrón y en el interior pre- 
senta una decoración, también pintada, a modo de manchas dispersas, de color más rojizo. Al estar la pieza incompleta no podemos precisar si forman parte de un motivo decorativo concreto. El diámetro de la boca es de $19 \mathrm{cms}$ y el del fondo de $12 \mathrm{cms}$.

Fig. $4 n^{\circ} 2$ : se trata de un ataifor, de cuerpo ligeramente carenado, rematado en un pequeño labio redondeado y rematado al exterior, con repie anular. A lo largo de la carena presenta una sencilla decoración consistente en dos incisiones algo profundas. La pasta es de color anaranjada, bastante bien decantada. El diámetro de la boca es de $30 \mathrm{cms}$ y el de la base de $1 \mathrm{I} \mathrm{cms}$.

\section{PIEZAS INCOMPLETAS}

En este apartado recogemos algunos ejemplos de piezas que, aunque no han aparecido completas sino muy fragmentadas, es posible reconstruir su forma originaria. Suponen una cierta novedad formal o decorativa de lo hasta ahora conocido en Vascos.

\section{Cantimplora}

Hasta el presente no se ha encontrado ninguna cantimplora completa aunque sí algunos fragmentos especialmente de la boca (IZQUIERDO, 1983 a: f. 23 n० 14; 1986 b: f. $3 n^{\circ} 19$ y f. 7 n०21). Por el fragmento que aquí presentamos podemos saber que su forma es la característica de este tipo de piezas: cuerpo redondeado y achatado -con una cara abombada y la otra algo más plana-, gollete en la parte superior rematado en una boca de labio exvasado y dos asas simétricas en los laterales (fig. $3 n^{\circ}$ 6). Por sus características formales, se trata de piezas que solamente se podrían colocar sobre una superficie por su parte plana. Lo normal es que, tanto en el interior de las viviendas como en el momento de transportar agua, estuviesen colgadas por una cuerda que pasase por las asas.

Cantimploras parecidas a éstas de Vascos, fechadas entre finales del siglo XII y principios del XIII, se encontraron en lijona (Alicante) (AZUAR, 1985: p. 74-77).

\section{Cántaro}

Es curioso que, a pesar de ser muy posiblemente la pieza de uso más cotidiano en Vascos -por la vital necesidad del transporte y almacenamiento de agua-, prácticamente no se ha encontrado ningún cántaro completo (IZQUIERDO, 1979: f. 5 nº I; 1986 a: p. I 19). Los fragmentos son abundantísimos, entre los que destacan las características asas de cinta que arrancan del borde hasta la parte superior de la panza, destinadas a soportar pesos de cierta consideración (IZQUIERDO, 1979: ff. 21 n ${ }^{\circ}$ | a 7, 22, 23, 24 y 25; 1983 a: ff. $20 n^{\circ} 24$ a 30 y 37 n 3; 1986 a: p. 1 19). Se trata de piezas de paredes con acanaladuras, bastante finas -posiblemente para aligerar su peso en vacío dado el tamaño y el consiguiente volumen interior-, que las debía de hacer bastante frágiles y las fracturas debían de ser muy frecuentes, inutilizándolas. No obstante, en algunas ocasiones, la parte inferior -que casi siempre presenta un abombamientose solía aprovechar, bien como comederos de animales domésticos en los patios de las casas o bien como tiestos haciéndoles una perforación en la parte central del fondo. En algunos lugares se utilizaron para llevar a cabo ciertas prácticas botánicas.

Aquí presentamos un fragmento de la boca de un ejemplar -con parte de su asa de cinta-, que ofrece la peculiaridad de tener decorada la parte superior de la panza, con unas incisiones onduladas enmarcadas por dos bandas de incisiones horizontales (fig. $5 n^{\circ}$ 2). La pasta es de color ocre blanquecino.

\section{Alcadafe}

Los alcadafes, lebrillos o barreños, al igual que los cántaros, también debieron de ser muy abundantes - dada la gran cantidad de fragmentos encontrados-, aunque tampoco han sido muchos los ejemplares mínimamente encontrados. Son piezas que formalmente apenas han evolucionado hasta nuestros días: perfil troncocónico invertido, con amplia boca rematada en un grueso labio redondeado muy remarcado al exterior (IZQUIERDO, 1979: ff. $3 \mathrm{n}^{\circ}$ I, 17 y $18 n^{\circ}$ I a 8; 1983 a: f. 20 n 15 a 18). La pasta, de regular calidad, siempre es de color rojiza. Nor- 
malmente suelen ser completamente lisos, aunque en ocasiones, como los ejemplares que aquí presentamos, pueden tener alguna decoración, incisa o en relieve.

Fig. $7 n^{\circ}$ I: parte superior de un alcadafe, de grueso labio redondeado y remarcado tanto al exterior como al interior, sobre el que se desarrolla una banda de incisiones onduladas. El diámetro es imposible de calcular. En la pared exterior también presenta una decoración de tres bandas de incisiones paralelas, entre las que se desarrollan sendas molduras con cortes verticales dejando a modo de pequeños cuadrados en relieve. En la cara interior de la pared también se desarrolla otra banda de incisiones onduladas. La pasta es de color rojiza. En algún otro ejemplar las molduras consisten en un cordón digitado.

Fig. $7 n^{\circ} 2$ : fragmento de borde de un alcadafe, de grueso labio redondeado remarcado al exterior, de 57 cms de diámetro; presenta una decoración de incisiones a peine -un grupo de incisiones onduladas enmarcadas por dos bandas de incisiones horizontales- tanto en la pared como en la parte superior del labio. La pasta es de color rojiza.

Fig. $7 n^{\circ}$ 3: parte inferior de un alcadafe, de $30 \mathrm{cms}$ de diámetro en la base; presenta la peculiaridad de tener una decoración incisa en la cara superior del fondo, consistente en un motivo decorativo en bandas, posiblemente cruciforme con un círculo central. En la mitad de la pared exterior también tiene otra banda con una incisión ondulada. La pasta es de color rojiza.

\section{Ataifores con asas}

Se trata de grandes ataifores o fuentes que tienen dos asas horizontales en la parte superior de la pared. El motivo de las mismas tal vez se debería a facilitar su manejo -sobre todo en las de mayor tamaño y peso-, pues la función de estas piezas posiblemente sería la misma que la de los demás ataifores. Al igual que éstos, la parte interior está decorada mientras que la exterior -incluidas las asas- está recubierta por un vidriado melado. Hasta ahora no se ha encon- trado ninguno mínimamente completo en VasCOS (IZQUIERDO, 1983 a: f. 28 n 3).

Aquí presentamos un fragmento correspondiente a la parte superior de un ataifor, de labio redondeado, de $33 \mathrm{cms}$ de diámetro, y pared carenada (fig. $5 \mathrm{n}^{\circ}$ I). Por debajo del labio conserva un asa horizontal de sección ovalada. En la parte interior, incluida la superficie del labio, se desarrolla una decoración en verde y manganeso, con la particularidad de que el color verde sólo se utiliza en el labio -pequeñas manchas- mientras que en el interior el motivo -geométrico- está elaborada solamente en manganeso sobre el fondo blanco. Toda la superficie exterior, incluida el asa, está recubierta por un vidriado melado amarillento.

Como ya señalara Sergio Martínez Lillo (MARTÍNEZ, 1990: p. 139), este tipo de ataifores con asas horizontales parece estar asociado a yacimientos de la zona toledana, habiéndose encontrado ejemplares, entre otros lugares, en Toledo (MARTíNEZ, 1986: lám. III b y c), Talavera de la Reina (RODRIGUEZ-MORALEDA, 1984: pp. 52 y 57, f. 16, I), Olmos (MARTíneZ, 1990: f. 2a), Alcalá de Henares (PAVON, 1982; ZOZAYA, 1983) y Guadalajara (PAVON, 1984).

\section{Jarrita}

Han sido bastante abundantes las jarritas hasta ahora encontradas en Vascos, la mayoría presentando una decoración de cuerda seca parcial en la parte superior del cuerpo (IZQUIERDO, 1979: ff. 46 n I I, 47, 48,50 y 5।; 1983 a: ff. 24 y 36 no I; 1994: f. 41 n 3). El ejemplar que aquí presentamos corresponde a una jarrita incompleta en su parte superior, por lo que no podemos precisar la forma originaria de la boca y del labio (fig. $6 n^{\circ}$ I). Tiene un fondo con repie anular, de $5 \mathrm{cms}$ de diámetro. Presenta dos asas simétricas, de sección ovalada, que arrancan del cuello hasta la parte más ancha del cuerpo. Es bastante panzuda en su mitad inferior, en la que se desarrolla una decoración de cuerda seca parcial, en una banda, de motivo geométrico de círculos irrregulares. Tiene un cuello bastante acusado y la boca también sería bastante ancha. 


\section{Discos}

Se trata de piezas de función desconocida, las cuales, entre otros usos, podrían haber servido para hornear el pan (GUTIERREZ, 1990-91; ROSELLO, 1991: p. 170). Ya habían aparecido anteriormente en Vascos (IZQUIERDO, 1983 a: f. 23 n $^{\circ} 3$ y 4), aunque los habíamos considerado como platos o platillos dada su sencilla forma: un fondo plano y una pequeña pared vertical (IZQUIERDO, 1986 a: pp. I2I-123; 1994: ff. 37 n 2 a 4 y 45 n 3). Normalmente son piezas hechas a mano, con una pasta de calidad bastante mala y quemada por el uso. Aquí presentamos un nuevo fragmento, de características similares, que, unido a otros, nos viene a confirmar la utilización de este tipo de piezas en Vascos (fig. $3 n^{\circ} 4$ ).

También presentamos otro ejemplar, hecho a mano y de pasta quemada, que tiene la peculiaridad de tener un pedúnculo en el centro (fig. $3 n^{\circ}$ 5). Posiblemente sirviese para que quedase un agujero en la parte central del pan una vez cocido.

Los discos (tabaq) corresponden a la serie 8 de Sonia Gutiérrez, siendo piezas destinadas a cocer tortas de pan ácimo o poco fermentado (1996: p. 139).

\section{Candil}

Han sido bastante abundantes los restos de candiles, más o menos completos, que se han encontrado en Vascos (IZQUIERDO, 1979: ff. 7 y 8 n 2, lám. XXII; 1983 a: f. 38, lám. IX n 5 y 7; 1986 b: f. 3 $\left.n^{\circ} 23\right)$. Todos ellos son los característicos de cazoleta con asa y piquera. El que aquí presentamos, aunque muy incompleto, ofrece la novedad de tener un apéndice vertical, de forma triangular, en al arranque de la piquera (fig. $6 n^{\circ}$ 2). Este aditivo, muy poco frecuente, parece indicar que se trata de una imitación de piezas metálicas. Este ejemplar presenta una decoración de cuerda seca parcial, muy mal conservada.

Ejemplares similares, recubiertos por un vidriado verdoso -lo que refuerza la idea de la imitación de piezas metálicas- se han encontrado en Murcia (NAVARRO, 1986: p. 166, f. nº 356 y p. 249, f. n 538) y en Benetússer (ESCRIBA, 1990: p. 65, f. $n^{\circ}$ C.8I).

\section{OTRAS PIEZAS}

En este apartado presentamos dos piezas, de características muy similares aunque, por encontrarse ambas fragmentadas, no podamos precisar su forma completa originaria (fig. $8 \mathrm{n}^{\circ}$ । y 2). Se trata de dos piezas zoomorfas, alargadas y huecas, que parecen haber pertenecido, más que a figuras de animales propiamente dichos, a cuellos de recipientes para verter líquidos, a modo de teteras o aguamaniles. El extremo queda rematado en una pequeña cabeza de animal, con orejas y ojos señalados, así como una cresta, y por cuya boca caería el líquido. A lo largo del cuello se desarrolla una decoración de cuerda seca parcial, simplemente de pequeños trazos morados o combinando también el color verde.

De Murcia procede un pitorro de un posible aguamanil, fechado en el siglo XIII, con forma de cabeza de animal con los ojos y la cresta modelados (NAVARRO, 1986: p. 248, f. n 535) y también una figura -aunque no hueca- representando un cuello y cabeza de equino, con orejas remarcadas y rasgos anatómicos pintados al manganeso (IDEM, p. 53, f. 108).

\section{CONCLUSIÓN}

Con algunas de las piezas aquí presentadas y otras que no se incluyen pero que han sido detectadas entre los hallazgos proporcionados por las excavaciones, la relación tipológica de la cerámica de Vascos que presentamos hace ya unos años (IZQUIERDO, 1986 a), se amplía considerablemente, a la par que se pueden precisar o rectificar algunos elementos. Así, por ejemplo, la serie que entonces denominamos "plato" (IZQUIERDO, 1986 a: pp. 121 - 123, f. 12) y de la que aquí también hemos presentado algunos ejemplares, habría más bien que identificarla con la serie "disco" de Roselló (199|: p. 170), correspondiente a piezas posiblemente utilizadas para hornear el pan.

En aquel análisis tipológico señalábamos quince series diferentes, muchas de ellas con diversas variantes -formales y decorativas-, lo que ya nos presentaba un panorama cerámico 
bastante amplio y diversificado. Después de los hallazgos producidos durante estos últimos años -algunos ya publicados y otros todavía inéditos-, a esa relación se le pueden añadir seis series nuevas (orza, cantimplora, taza, arcaduz, anafe y cuenco), lo que eleva a veintiuna las que hasta el momento parecen estar confirmadas en Vascos. Y tal vez puedan ser algunas más, pero lo exiguo de muchos fragmentos cerámicos no nos permite poder precisar, con un mínimo de seguridad, la forma y función originaria de las piezas.

A modo de síntesis, las series conocidas en Vascos podían quedar agrupadas de la siguiente manera:

- piezas de cocina:

olla o marmita

colador

(posible cuscusera)

cazuela

tapadera

anafe

discos para pan

- piezas de almacenamiento, transporte y conservación de líquidos o alimentos:

orza

tinaja

cántaro

cantimplora

arcaduz

alcadafe

- piezas de mesa:

ataifor/jofaina

cuenco

jarro/jarrito

jarra/jarrita

taza/copa

redoma

limeta

- piezas para iluminación: candil

- piezas complementarias: bote

De toda esta producción cerámica, que nos pone en contacto con un variado ajuar doméstico, no hemos encontrado hasta el momento ningún elemento que nos pueda indicar que, al menos, parte de la misma, pudiese haber estado fabricada en Vascos. Es posible que algunas piezas que parecen estar hechas a mano pudiesen corresponder a una producción local, pero que sería muy limitada o correspondiente a los primeros momentos de asentamiento islámico en el lugar. No obstante, aunque hasta el presente no hayan aparecido pruebas confirmatorias, no descartamos la existencia de algún alfar, cuya producción iría orientada, muy probablemente, a la fabricación de las piezas de uso más cotidiano y necesario, como son las relacionadas con la cocina.

\section{BIBLIOGRAFÍA}

AGUADO VILLALBA, José (199|): Tinajas medievales españolas. Islámicas y mudéjares, Toledo.

AZUAR RUIZ, Rafael (1985): Castillo de la Torre Grossa (lijona), Alicante.

ESCRIBA, Felisa (1990): La cerámica califal de Benetússer, Valencia.

GUTIÉRREZ LLORET, Sonia (1990-9I): "Panes, hogazas y fogones portátiles. Dos formas cerámicas destinadas a la cocción del pan en al-Andalus: el homillo (tannur) y el plato (tabag)", Lucentum. IX-X. |6|-|75.

GUTIÉRREZ LLORET, Sonia (1996): La cora de Tudmir de la antigüedad tardía al mundo islámico. Poblamiento y cultura material, Madrid-Alicante.

IZQUIERDO BENITO, Ricardo (I 979): "Excavaciones en la ciudad hispanomusulmana de Vascos (Navalmoralejo, Toledo). Campañas 1975-1978", Noticiario Arqueológico Hispánico. 7. 247-392.

IZQUIERDO BENITO, Ricardo (1983 a): "Ciudad hispanomusulmana de Vascos (Navalmoralejo, Toledo). Campañas 1979-1980", Noticiario Arqueológico Hispánico. 16. 289380.

IZQUIERDO BENITO, Ricardo (I983 b): "La cerámica hispanomusulmana decorada de Vascos (Toledo), Homenaje al Prof. Martín Almagro Basch. IV. I07-I I 5.

IZQUIERDO BENITO, Ricardo (1986 a): "Tipología de la cerámica hispanomusulmana de Vascos (Toledo)", Segundo Coloquio Internacional de Cerámica Medieval en el Mediterráneo Occidental, I13-125.

IZQUIERDO BENITO, Ricardo (1986 b): "Los baños árabes de Vascos (Navalmoralejo, Toledo)", Noticiario Arqueológico Hispánico. 28. 193-242. 
IZQUIERDO BENITO, Ricardo ( 1987): "La cerámica común de Vascos. Estudio estadístico", Actas del II Congreso de Arqueología Medieval Española. II. 7| |-7| 8.

IZQUIERDO BENITO, Ricardo ( 1994): Excavaciones en la ciudad hispanomusulmana de Vascos (Navalmoralejo, Toledo). Campañas 1983-1988. Toledo.

MARTÍNEZ LILLO, Sergio (1986): "Horno cerámico islámico núm. I del circo romano de Toledo", Actas del I Congreso de Arqueología Medieval Española. IV. 73-93.

MARTÍNEZ LILLO, Sergio ( 1990): "El poblado fortificado de Olmos (Walmus)". Madrid del siglo IX al XI. I3 I- | 40.

NAVARRO PALAZON, Julio (1986): La cerámica islámica de Murcia. Volumen I: Catálogo, Murcia.

PAVÓN MALDONADO, Basilio (1982): Alcalá de Henares medieval. Arte islámico y mudéjar, Madrid.

PAVÓN MALDONADO, Basilio (1984): Guadalajara medieval. Arte y arqueología árabe y mudéjar, Madrid.
RETUERCE VELASCO, Manuel (1984): "La cerámica islámica de Calatalifa. Apuntes sobre los grupos cerámicos de la Marca Media", Boletín del Museo Arqueológico Nacional (Madrid). II. I I7-I36.

RODRÍGUEZ SANTAMARIA, Antonio-MORALEDA OLIVARES, Alberto (1984): Cerámicas medievales decoradas de Talavera de la Reina, Talavera de la Reina.

ROSELLÓ-BORDOY, Guillermo (1978): Ensayo de sistematización de la cerámica árabe de Mallorca. Palma de Mallorca.

ROSELLÓ-BORDOY, Guillermo (1991): El nombre de las cosas en al-Andalus: una propuesta de terminología cerámica. Palma de Mallorca.

ZOZAYA, Juan (1983): "Excavaciones arqueológicas en Qalat'Abd al-Salam (Alcalá de Henares, Madrid)". Noticiario Arqueológico Hispánico. 17. 41 I-529. 


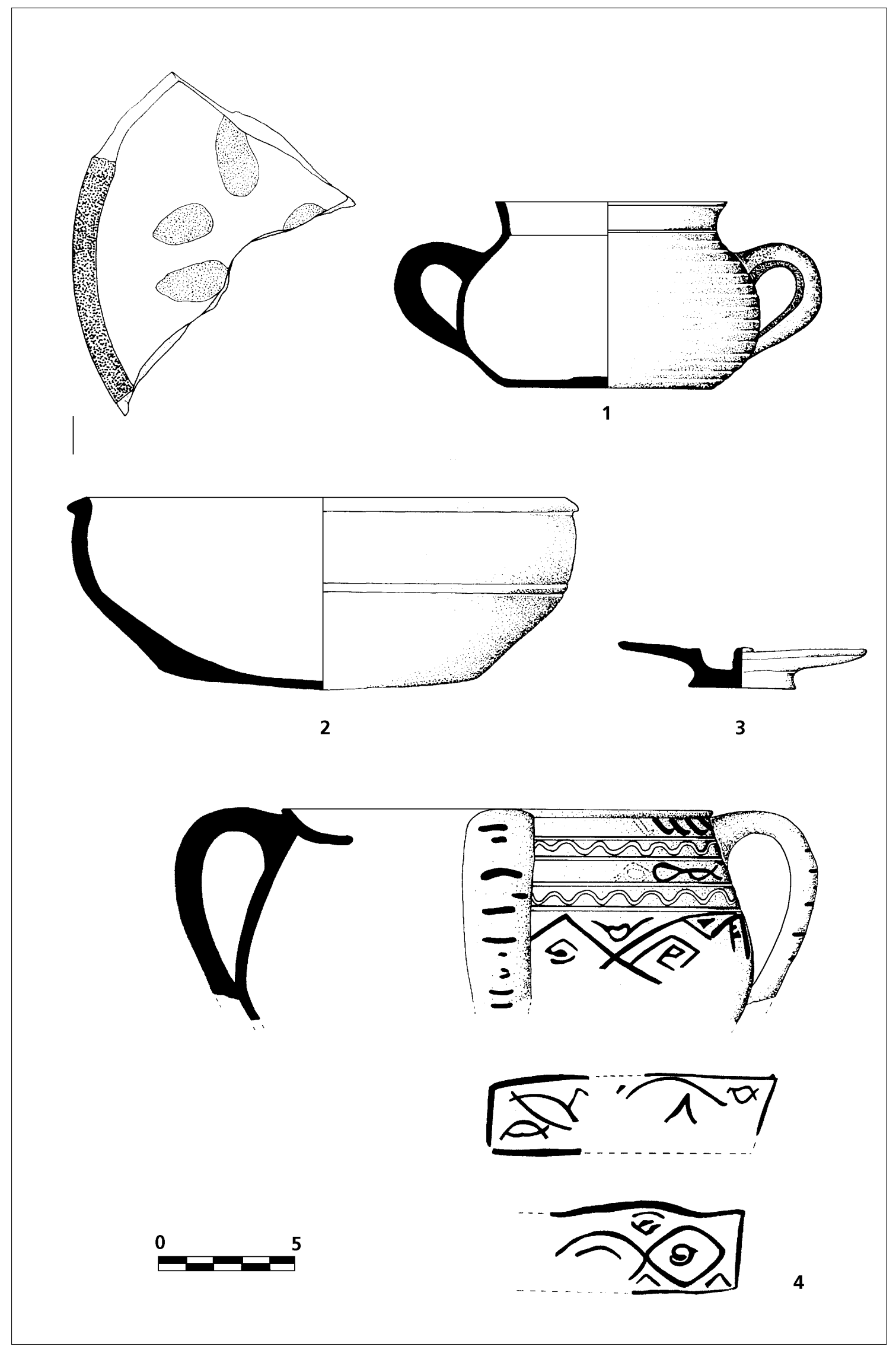

Fig. I: Piezas diversas 


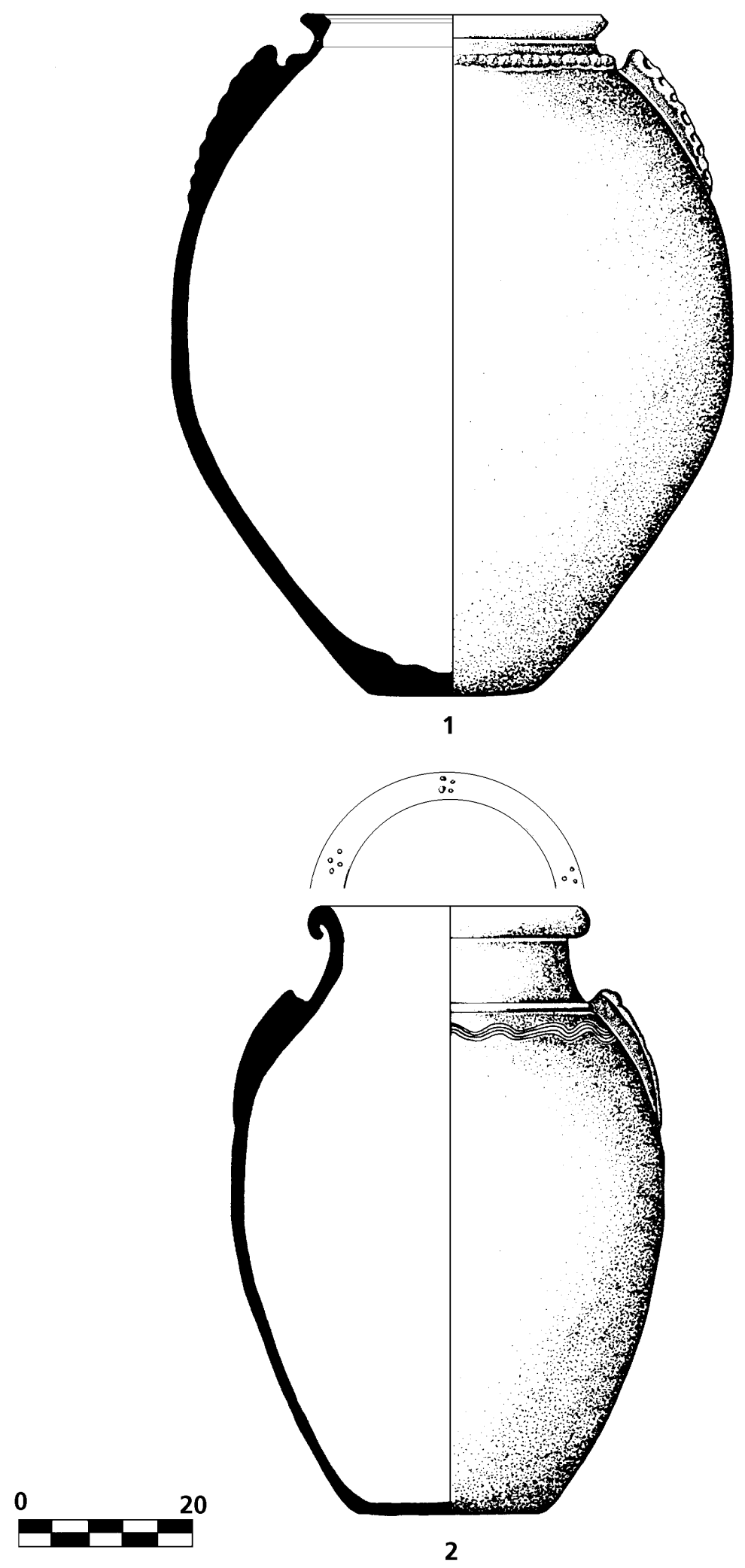

Fig. 2: Tinajas 


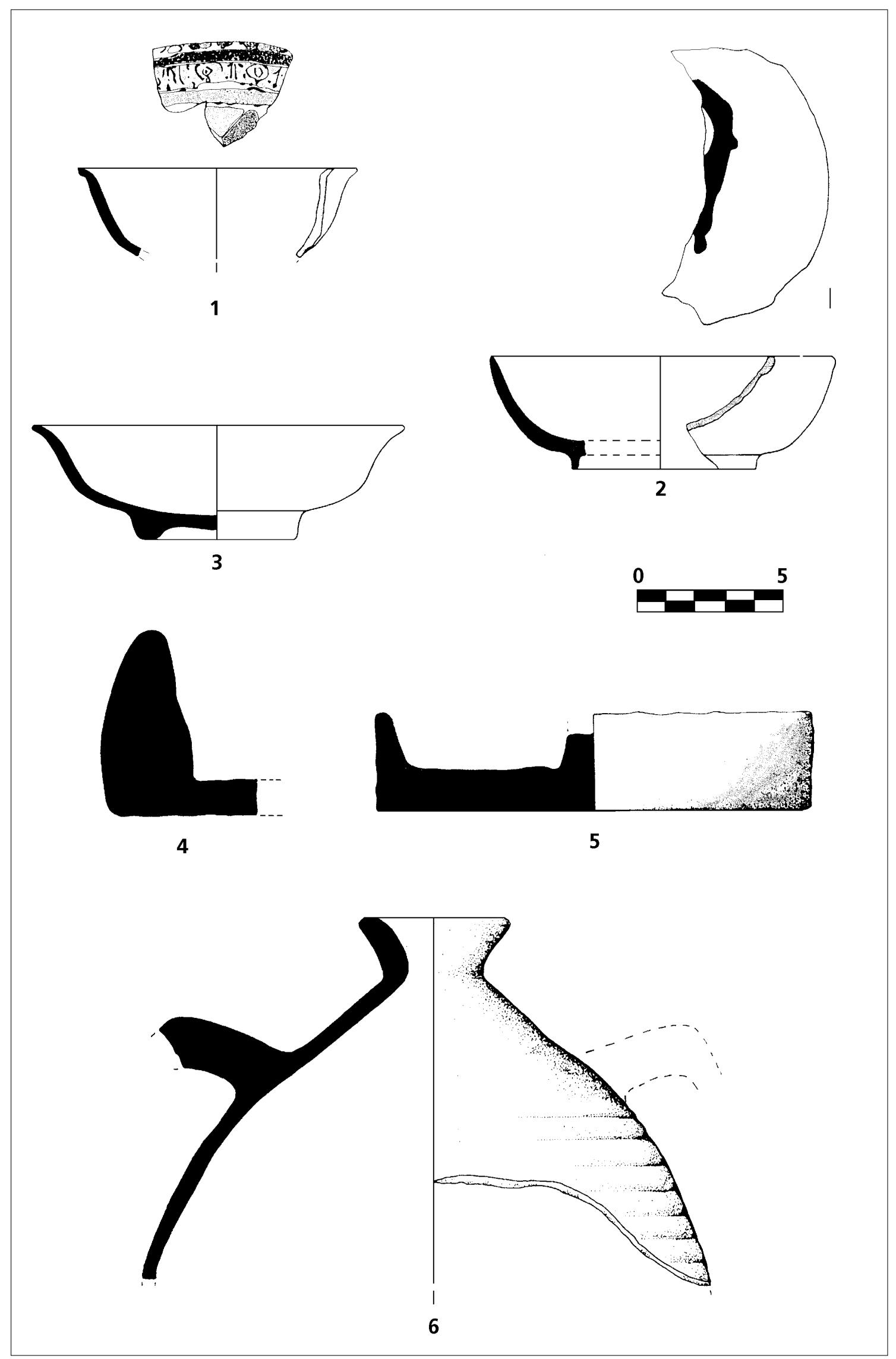

Fig. 3: Piezas diversas 




Fig. 4: $\mathbf{n}^{\circ}$ I: cazuela; $n^{\circ}$ 2: ataifor

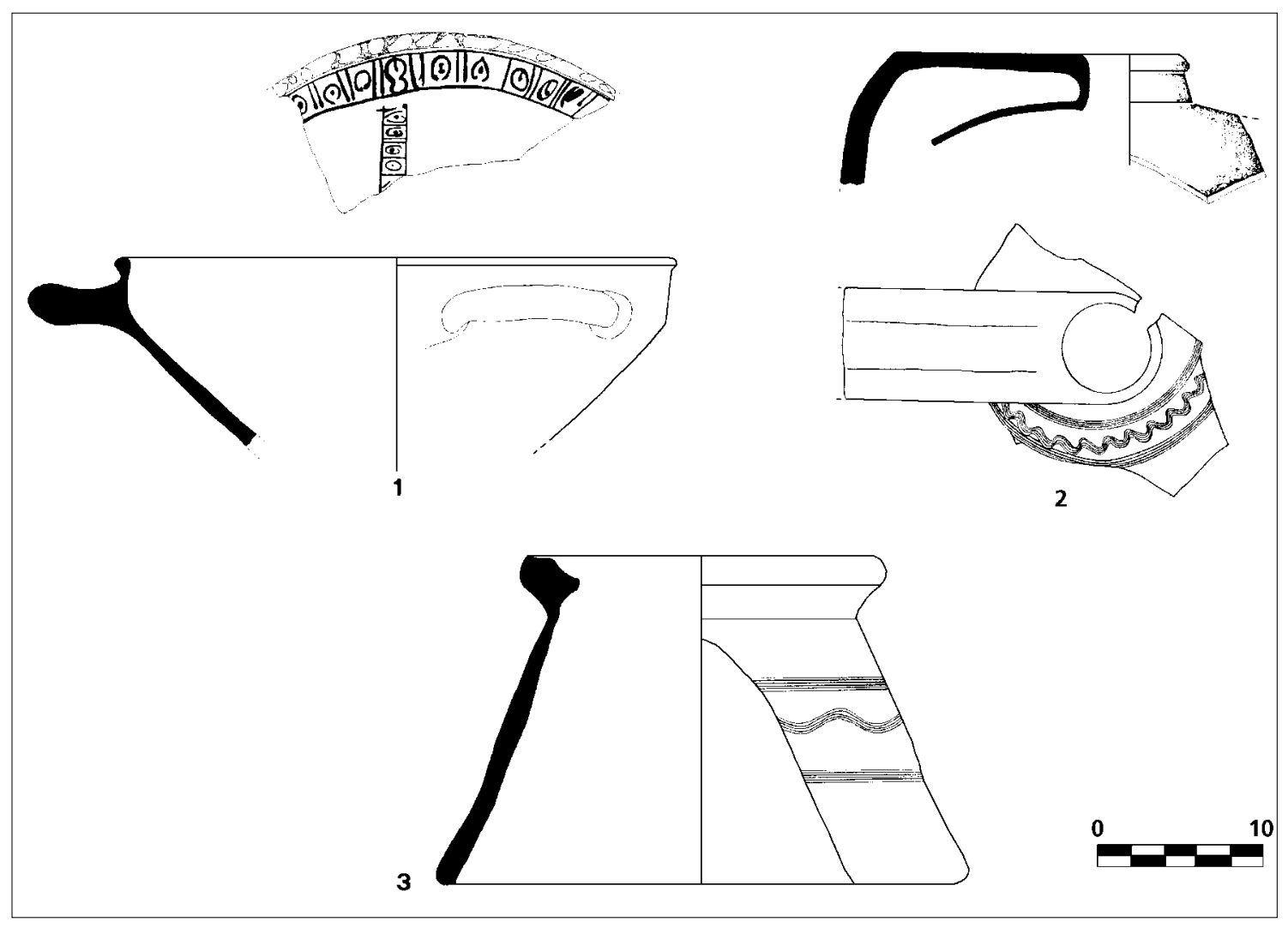

Fig. 5: Piezas diversas 


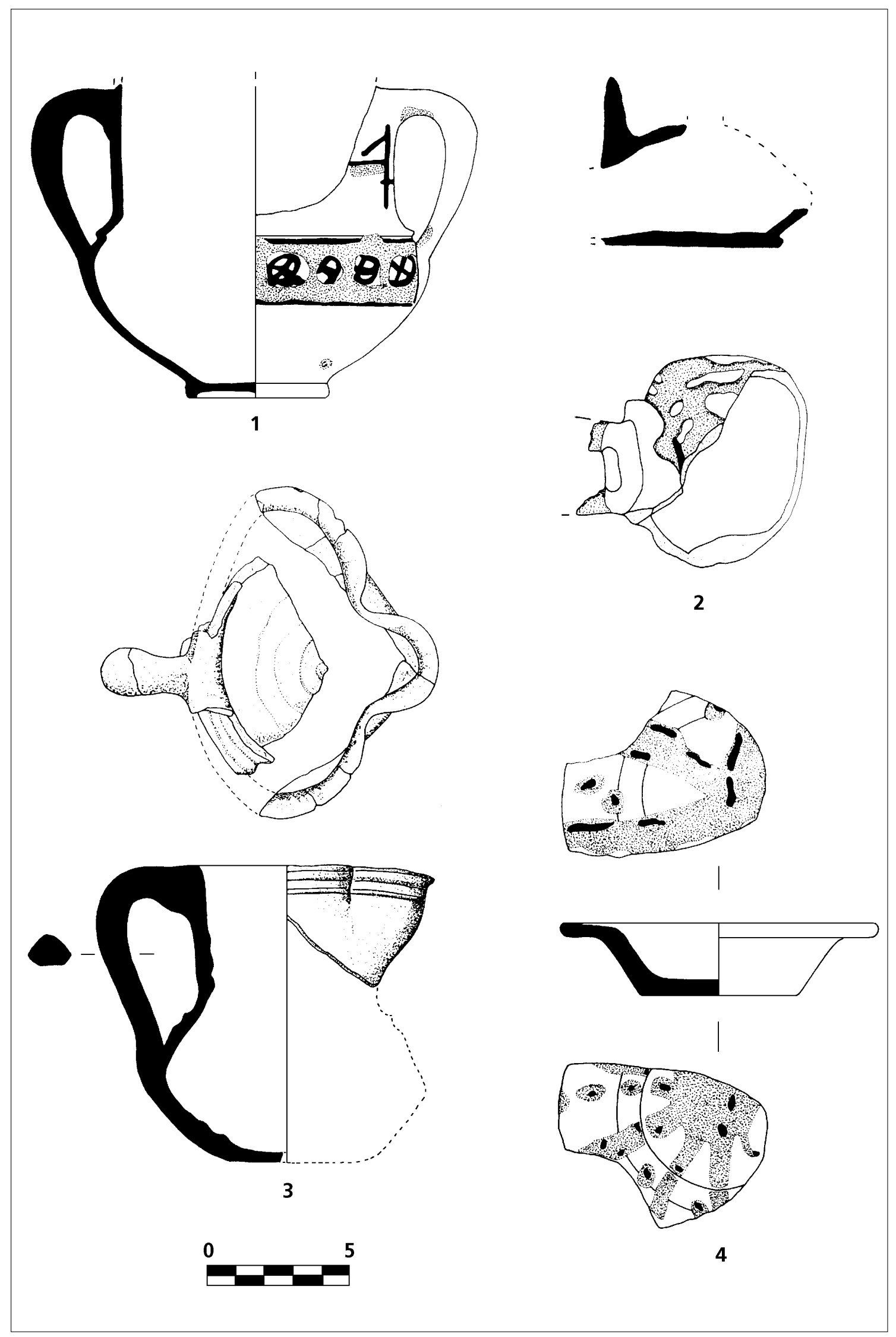

Fig. 6: Piezas diversas 


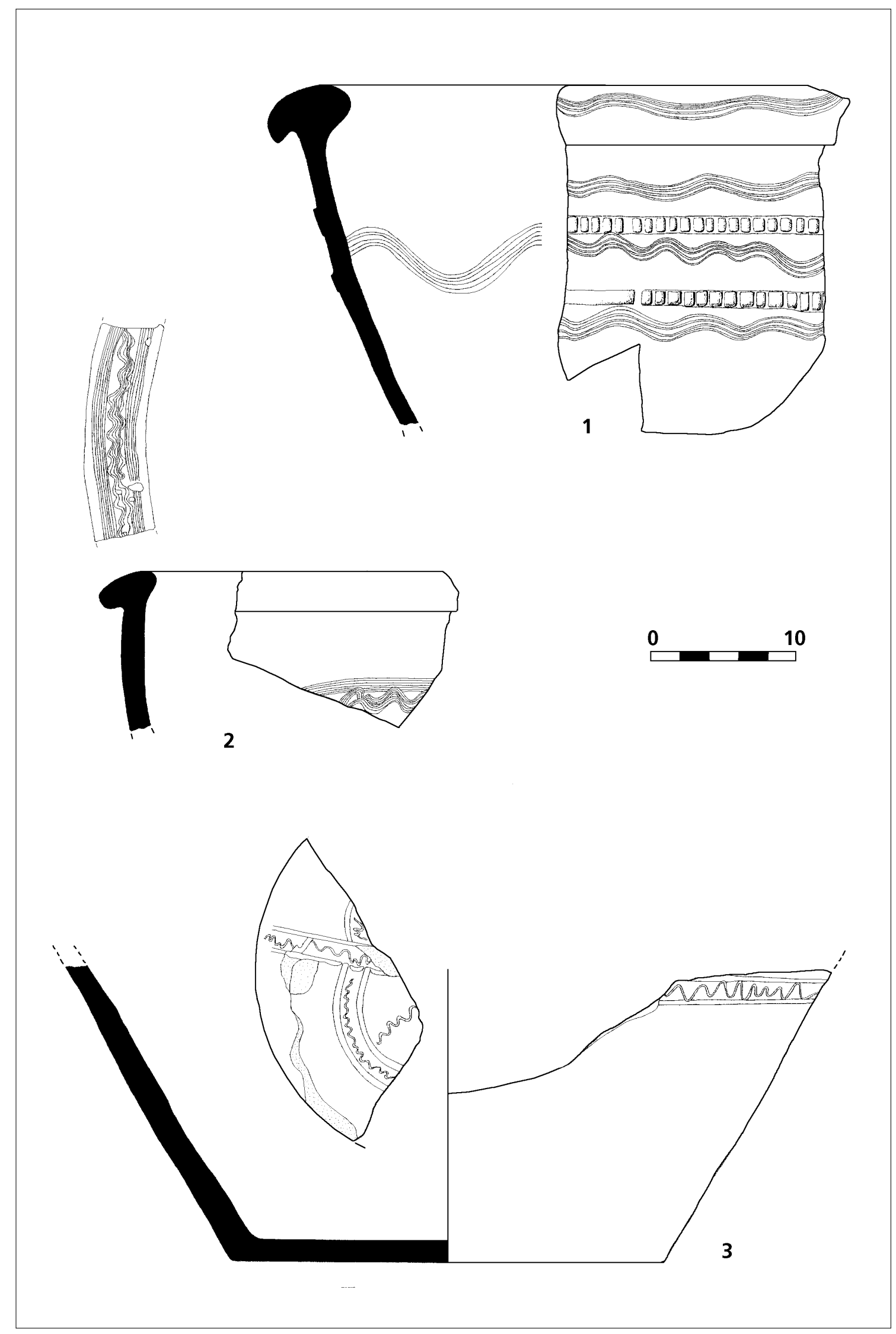

Fig. 7: Fragmentos de alcadafes 

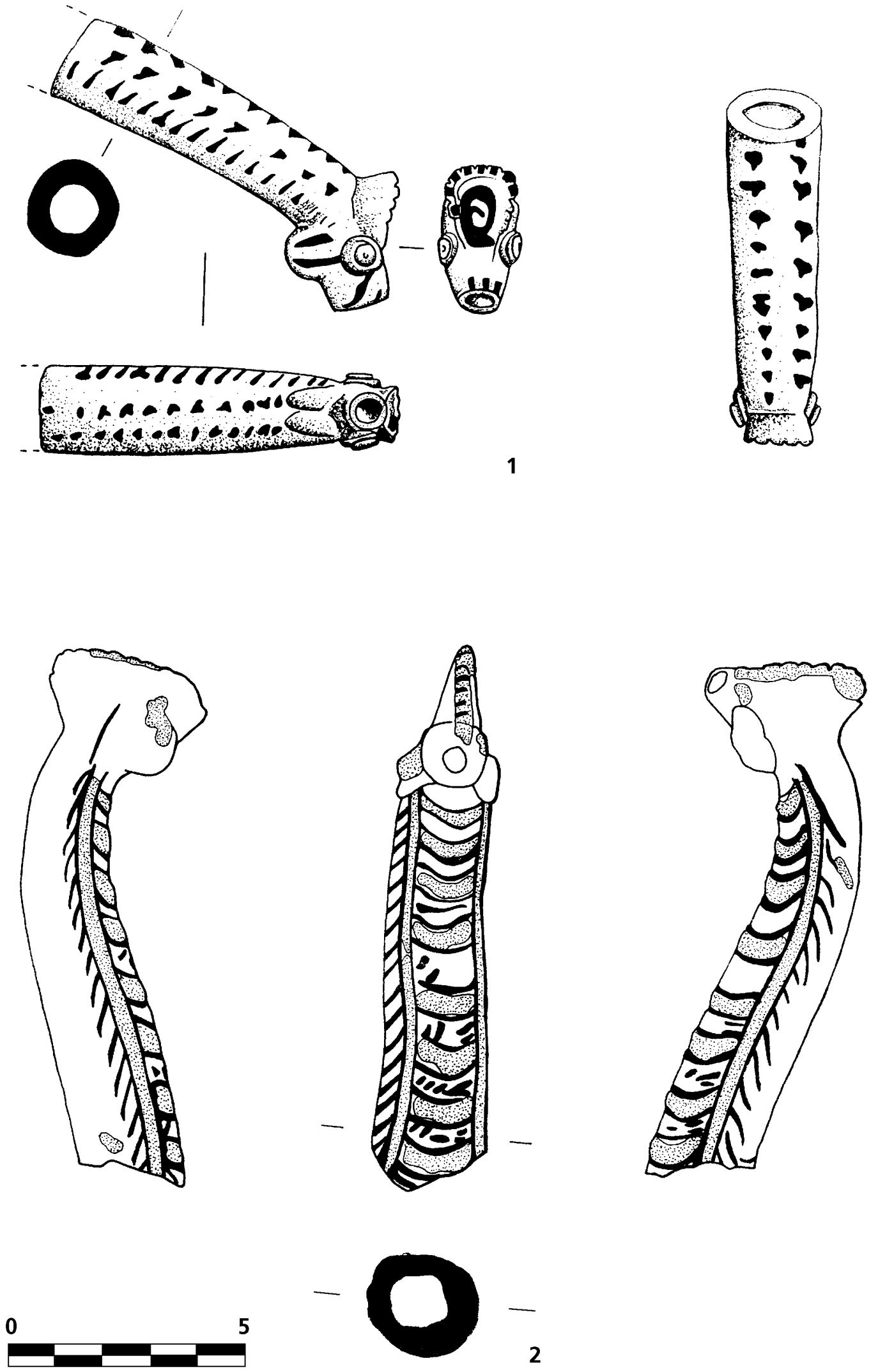

Fig. 8: Cuellos de aguamanil, zoomorfos, con decoración de cuerda seca parcial 